\title{
Brainstem Auditory Evoked Potential Abnormalities In Hypothyroidism
}

\author{
JhambShikha,SinghKamal Dev, Kumar Avnish \\ Department of Physiology, Government Medical College, Patiala, Punjab, India
}

\begin{abstract}
Background: Hypothyroidism represents a syndrome complex in which multiple organ systems, including the central nervous system, are affected. Aim: The study was conducted to determine the changes in brainstem auditory evoked potentials in patients with hypothyroidism.

Materials and methods: A case control study was conducted on 50 known cases of hypothyroidism, aged 20-50 years, and 50 healthy, age-matched, normal subjects. Brainstem auditory evoked potentials were recorded and results were analysed statistically using student's paired t-test. The data consisted of wave latencies I,II,III,IV, $V$; interpeak latencies I-III,I-V,III-V and amplitudes Ia,Va, V/I, separately for both ears.

Results: The latency of wave $V$ was significantly delayed bilaterally, the interpeak latency III-V was significantly delayed in right ear, amplitude Ia was highly significantly shortened in left ear, while amplitudes Va and V/I were highly significantly shortened bilaterally, in hypothyroid patients as compared to controls. However, no significant differences were observed between hypothyroid and control groups as regards to wave latencies I,II,III,IV bilaterally; interpeak latencies I-III,I-V bilaterally, interpeak latency III-V in left ear; and amplitude Ia in right ear.

Conclusion: Hypothyroid patients have an involvement of auditory pathway, which can be detected with fair accuracy with auditory evoked potential studies.
\end{abstract}

Keywords: BAEP,Evoked potentials, Hypothyroidism

\section{Introduction}

Hypothyroidismis the disease state that results from thyroid hormone deficiency ${ }^{[1]}$ Iodine deficiency remains the most common cause of hypothyroidism worldwide. In areas of iodine sufficiency, autoimmune disease (Hashimoto's thyroiditis) and iatrogenic causes (treatment of hyperthyroidism) are most common. ${ }^{[2]}$ Hypothyroidism is often initiated by autoimmunity against the thyroid gland (Hashimoto disease), but immunity that destroys the gland rather than stimulates it. This causes progressive deterioration and finally fibrosis of the gland, with resultant diminished or absent secretion of thyroid hormone ${ }^{[3]}$ Positron emission tomography (PET) brain scans of hypothyroid patients before and after $\mathrm{T}_{4}$ therapy demonstrate reversible reduced glucose uptake in specific brain areas, such as the limbic system, which also correlates with behavioral and psychiatric symptoms. ${ }^{[4]}$ Auditory acuity reduction has been associated with thyroid gland dysfunction and has been described by numerous authors. In 1974, Ritter stressed that hearing loss can be the most common otorhinolaryngological manifestation of congenital and acquired hypothyroidism, and auditory symptoms may happen alone or in association with vertigo and tinnitus. ${ }^{[5]}$ It is known that in this hormonal disorder there is a reduction in cell energy production, compromising the microcirculation and, consequently, oxygenation and the metabolism of the involved organs. Inner ear structures are also affected such as the striavascularis and the Organ of Corti ${ }^{[6]}$ Thyroid hormones control protein synthesis, the production of myelin and enzymes and the level of lipids in the central nervous system. Moreover, $\mathrm{T}_{4}$ can act as a neurotransmitter. Thus, it is believed that under hypothyroidism, hearing impairment can originate in the cochlea in the central auditory pathways and/or in the retrocochlearregion. ${ }^{[7]}$ Tonal threshold audiometry, Immittance tests and electrophysiological methods such as brainstem auditory evoked potentials (BAEP) and otoacoustic emissions (OAE) have been used to assess patients with hypothyroidism. ${ }^{[8]}$ Conventional audiometric tests are not sensitive enough to detect the initial phases of sensory loss, nor are they capable of determining the site and pattern of this hearing loss. ${ }^{[9]}$ The changes in neural generator activity and sensory conduction in CNS could be detected by monitoring auditory evoked potentials. Waves of ABR primarily represent volume conducted electrical activity generated from cochlear nerve to inferior colliculus and interpeak latencies between these waves reflect neural conduction in the corresponding segment of central auditory pathway. ${ }^{[10]}$ B AEP is a simple, non-invasive procedure to detect early impairment of acoustic nerve, and CNS pathways, even in the absence of specific symptoms. ABR is a far field recording of the synchronized response of a large number of neurons in the lower portion of auditory pathway ${ }^{[11]}$ Brainstem auditory evoked response is the potential recorded from the ear and vertex in response to a brief auditory stimulation to assess the conduction through auditory pathway up to midbrain. ${ }^{[12]}$ 
Typically the BAEPs comprise of five or more waveforms that are recorded within 10 milliseconds of an acoustic stimulus. Wave I originates from the peripheral portion of cranial nerve VIII (auditory nerve) near the cochlear nucleus. Wave II originates from cochlear nucleus, wave III from superior olivary nucleus, wave IV from lateral lemniscus and wave $\mathrm{V}$ from inferior colliculi in the midbrain. ${ }^{[13]}$

The aim of the present study was to assess the BAEP abnormalities in patients suffering from hypothyroidism in the age group 20-50 years, and to find whether any correlation exists between the observed abnormalities and the hypothyroid status.

\section{Materials And Methods}

The study was conducted in the Department of Physiology in the institute from 2012-2014. The subjects were divided into two groups (i) the hypothyroid group, and (ii) the control group. The study protocol was approved from the ethical committee of the institute. Written consent was obtained from all the enrolled subjects after explaining them the details of the study in their own language.The hypothyroid group comprised of 50 patients attendingoutdoor clinics of the institute, while the control group consisted of 50 age-matched volunteers from among the paramedical and lower staff of the institute.

\subsection{Inclusion criteria}

Among the first group, those with hypothyroidism, aged 20-50 years and with no past/present or family history of ear disease or deafness were included. The diagnostic method for hypothyroidism was based on T3, T4 and TSH levels. Among the controls, non-hypothyroid, age-matched subjects who had no past/present or family history of ear disease or deafness and who were audiometrically normal, euthyroid and apparently healthy, were included. We did not include subjects above 50 years of age since this age group has an increased incidence of presbycusis, a type of sensorineural hearing loss.

\subsection{Exclusion criteria}

For both the groups, those subjects were excluded, who had features of conductive deafness, ontological disorders, past history of neurological disorders, family history of deafness or any systemic illness that might affect the nervous system ( diabetes,uraemia, stroke, hepatic encephalopathy, multiple sclerosis etc.), had undergone prior ear surgery, had used known ototoxic medications (eg. aminoglycosides) or any drug which might affect the normal functioning of the nervous system (eg. antidepressants, antipsychotics, methyldopa etc.), who had hearing loss since childhood or had any genetic syndrome. In the control group, in addition to the above criteria, those subjects were also excluded, who gave past/family history of thyroid disease.

1.3 Medical and Biochemical examination

Prior to the BAEP recordings, all the subjects were made to undergo the following:

1.3.1 Detailed history by way of self administered questionnaires about medical history and lifestyle.

1.3.2 Detailed general physical and systemic examination.

1.3.3 Complete ENT checkup by way of otoscopic examination and tuning fork tests, to rule out peripheral hearing loss.

1.3.4 Serum T3, T4 and TSH levels, which were assessed in the clinical biochemistry lab of the institute.

\subsection{Brainstem auditory evoked potential study}

It was performed as per the guidelines of American Clinical Neurophysiological Society ${ }^{[14]}$. The subjects were asked to wash hair, the night before the test. This was to reduce unnecessary impedance which is produced by excessive oil present on scalp hair.For the test RMS EMG EP MARK II was used. BAER was performed as per the procedure given in the manual supplied by RMS Recorders and Medicare Systems (P) Ltd. The room was sound proof with quiet surroundings. The subject was allowed to relax on a comfortable chair with the subject's back towards the recording machine.The following anthropometric parameters were measured:

- Height (cms) and Weight (kgs)

\subsection{Statistical analysis}

Evaluation of the data was carried out by Microsoft Excel \& SPSS/PC+. 'p' value less than 0.05 and 0.01 were considered significant and highly significant respectively.

\section{Results}

There was no statistically significant difference between the basic data: age and height of both hypothyroid patients and controls. However, there was a statistically highly significant difference between the weight of both the groups, the values being much higher in hypothyroid patients as compared to 
controls(TABLE 1). Also, there was a statistically highly significant difference in plasma T3, T4 and TSH values for both the groups, T3 and T4 being much lower, and TSH being much higher in hypothyroid patients as compared to normal, healthy subjects(TABLE 2).

A comparison between the mean values of various wave latencies was done separately for both the ears, in both the hypothyroid and control groups(TABLE 3). No significant differences were observed between absolute latencies of waves I, II, III and IV in hypothyroid patients and controls, with either right ear or left ear stimulation. The latency of wave $\mathrm{V}$ was, however, significantly higher in hypothyroid patients as compared to controls, for both right ear, as well as left ear stimulation.

As regards to theInterpeak latency (IPL) comparison, no statistically significant differences were observed between IPLs I-III and I-V in hypothyroid and control groups, with either right ear or left ear stimulation. IPL III-V was significantly higher in hypothyroid group as compared to control group, with right ear stimulation, while it was comparable between hypothyroid and control groups in case of left ear stimulation(TABLE 4).

A comparison between the amplitudes of waves I (Ia) and V(Va), and absolute amplitude, R(V/I) was also done separately for both the ears, in both hypothyroid and control groups(TABLE 5). The amplitude Ia was comparable between hypothyroid and control groups in case of right ear stimulation, while it was highly significantly lower in hypothyroid group as compared to control group with left ear stimulation. The amplitude Va was highly significantly lower in hypothyroid group as compared to control group, with either right ear or left ear stimulation. Also, the absolute amplitude R (V/I) was highly significantly lower in hypothyroid group as compared to control group, with either right ear or left ear stimulation.

Table 1comparison Of Age, Height \& Weight Of Both Controls And Cases

\begin{tabular}{|l|l|l|l|l|}
\hline Parameters & $\begin{array}{l}\text { Controls } \\
\text { Mean } \pm \text { SD }\end{array}$ & $\begin{array}{l}\text { Cases } \\
\text { Mean } \pm \text { SD }\end{array}$ & $\begin{array}{l}\text { Value of } \\
\text { p }\end{array}$ & Inference \\
\hline Age (yrs) & $42.14 \pm 7.62$ & $40.2 \pm 7.62$ & 0.21 & NS \\
\hline Height $(\mathrm{cms})$ & $159.5 \pm 8.01$ & $159.48 \pm 8.04$ & 0.99 & NS \\
\hline Weight $(\mathrm{kgs})$ & $67.38 \pm 11.74$ & $75.16 \pm 15.04$ & $<0.01$ & HS \\
\hline
\end{tabular}

(NS: $\mathrm{p}>0.05$, Significant: $\mathrm{p}<0.05, \mathrm{HS}: \mathrm{p}<0.01$ )

Table 2 Comparison Of $\mathrm{T}_{3}, \mathrm{~T}_{4}$ And Tsh Levels Of Both Controls And Cases

\begin{tabular}{|l|l|l|l|l|}
\hline Parameter & $\begin{array}{l}\text { Controls } \\
\text { Mean } \pm \mathrm{SD}\end{array}$ & $\begin{array}{l}\text { Cases } \\
\text { Mean } \pm \mathrm{SD}\end{array}$ & $\begin{array}{l}\text { Value of } \\
\mathrm{P}\end{array}$ & Inference \\
\hline $\mathrm{T}_{3}(\mathrm{ng} / \mathrm{ml})$ & $1.01 \pm 0.28$ & $0.36 \pm 0.06$ & $<0.01$ & HS \\
\hline $\mathrm{T}_{4}(\mu \mathrm{g} / \mathrm{dl})$ & $7.45 \pm 1.92$ & $3.44 \pm 0.48$ & $<0.01$ & HS \\
\hline $\mathrm{TSH}(\mu \mathrm{IU} / \mathrm{ml})$ & $1.42 \pm 0.76$ & $4.71 \pm 0.38$ & $<0.01$ & HS \\
\hline
\end{tabular}

(NS: $\mathrm{p}>0.05$, Significant: $\mathrm{p}<0.05, \mathrm{HS}: \mathrm{p}<0.01)$

Table 3 Comparison Of Brainstem Auditory Evoked Potential Latencies (Msec) Between Hypothyroid And Control Groups

\begin{tabular}{|l|l|l|l|}
\hline BAEP latencies & $\begin{array}{l}\text { Hypothyroid group } \\
\text { Mean } \pm \text { SD }\end{array}$ & $\begin{array}{l}\text { Control group } \\
\text { Mean } \pm \text { SD }\end{array}$ & P value \\
\hline Right ear & & & \\
\hline I & $1.60 \pm 0.32$ & $1.59 \pm 0.14$ & 0.87 \\
\hline II & $2.61 \pm 0.28$ & $2.61 \pm 0.21$ & 0.92 \\
\hline III & $3.54 \pm 0.30$ & $3.53 \pm 0.18$ & 0.89 \\
\hline IV & $4.70 \pm 0.36$ & $4.60 \pm 0.24$ & 0.12 \\
\hline V & $5.52 \pm 0.37$ & $5.38 \pm 0.21$ & 0.02 \\
\hline Left ear & & & \\
\hline I & $1.55 \pm 0.28$ & $1.53 \pm 0.11$ & 0.69 \\
\hline II & $2.55 \pm 0.24$ & $2.55 \pm 0.18$ & 0.88 \\
\hline III & $3.53 \pm 0.29$ & $3.50 \pm 0.19$ & 0.56 \\
\hline IV & $4.72 \pm 0.42$ & $4.68 \pm 0.20$ & 0.54 \\
\hline V & $5.60 \pm 0.55$ & $5.42 \pm 0.17$ & 0.03 \\
\hline
\end{tabular}

(NS: $p>0.05$, Significant: $p<0.05$, HS: $p<0.01$ )

Table 4 Comparison Of Interpeak Latencies (Msec) Between Hypothyroid And Control Groups

\begin{tabular}{|l|l|l|l|}
\hline $\begin{array}{l}\text { Interpeak } \\
\text { Latencies }\end{array}$ & $\begin{array}{l}\text { Hypothyroid group } \\
\text { Mean } \pm \text { SD }\end{array}$ & $\begin{array}{l}\text { Control group } \\
\text { Mean } \pm \text { SD }\end{array}$ & P value \\
\hline Right ear & & & \\
\hline I-III & $1.94 \pm 0.38$ & $1.94 \pm 0.21$ & 0.98 \\
\hline I-V & $3.92 \pm 0.44$ & $3.79 \pm 0.22$ & 0.08 \\
\hline III-V & $1.98 \pm 0.31$ & $1.85 \pm 0.25$ & 0.02 \\
\hline Left ear & \multicolumn{3}{|l}{} \\
\hline
\end{tabular}


Brainstem Auditory Evoked Potential Abnormalities In Hypothyroidism

\begin{tabular}{|l|l|l|l|}
\hline I-III & $1.99 \pm 0.35$ & $1.98 \pm 0.22$ & 0.85 \\
\hline I-V & $4.05 \pm 0.57$ & $3.89 \pm 0.17$ & 0.06 \\
\hline III-V & $2.06 \pm 0.58$ & $1.92 \pm 0.24$ & 0.10 \\
\hline
\end{tabular}

(NS: $\mathrm{p}>0.05$, Significant: $\mathrm{p}<0.05$, HS: $\mathrm{p}<0.01$ )

Table 5 Comparison Of Amplitudes ( $\mu$ V) Of Waves I (IA), V (VA) And Absolute Amplitude R (V/I)

Between Hypothyroid And Control Groups

\begin{tabular}{|l|l|l|l|}
\hline Amplitudes & $\begin{array}{l}\text { Hypothyroid group } \\
\text { Mean } \pm \text { SD }\end{array}$ & $\begin{array}{l}\text { Control group } \\
\text { Mean } \pm \text { SD }\end{array}$ & P value \\
\hline Right ear & & & \\
\hline Ia & $1.93 \pm 0.67$ & $2.36 \pm 1.59$ & 0.08 \\
\hline Va & $1.95 \pm 0.66$ & $2.86 \pm 1.87$ & 0.001 \\
\hline R & $1.06 \pm 0.33$ & $1.33 \pm 0.69$ & 0.012 \\
\hline Left ear & & & \\
\hline Ia & $2.04 \pm 0.69$ & $3.62 \pm 0.73$ & $<0.01$ \\
\hline Va & $2.02 \pm 0.66$ & $5.13 \pm 0.82$ & $<0.01$ \\
\hline R & $1.15 \pm 0.64$ & $1.46 \pm 0.31$ & 0.003 \\
\hline
\end{tabular}

(NS: $\mathrm{p}>0.05$, Significant: $\mathrm{p}<0.05$, HS: $\mathrm{p}<0.01$ )

\section{Discussion}

The results of our study have shown that absolute latency of wave $\mathrm{V}$ was significantly delayed bilaterally, and IPL III-V was significantly delayed unilaterally, in hypothyroid patients as compared to controls. Also, the amplitude of wave I (Ia) was highly significantly shortened unilaterally, while amplitude of wave V (Va) and absolute amplitude R (V/I) were highly significantly shortened bilaterally, in hypothyroid patients as compared to controls.

Our findings support the results obtained by Chou et al, Figueiredoet al, KarlosThiago et al and Chandrashekhar et al; regarding significant delay in absolute latency of wave $\mathrm{V}$ in hypothyroid patients. However, we did not observe any significant delay in absolute latency of wave I, which was observed by Chou et al. Also, we did not find any significant delay in absolute latency of wave III, which was observed by Chou et $a l$,Figueiredoet al andChandrashekharet al. Our findings also support the results obtained by Figueiredo $e t a l$, regarding the significant prolongation of interpeak latency III-V in hypothyroidism. However, we did not observe any delay ininterpeak latencies I-III and III-V in hypothyroidism, while it was reported by Figueiredoet al. Our findings also support the results obtained by Anjanaet al, Thornton et al and Chandrashekharet al; regarding significant shortening of amplitudes Ia, Va and V/I. However, these changes in amplitudes of waves were not observed by Chou et al, Figueiredoet al and KarlosThiagoet al.

Deafness is the most common otolaryngological manifestations associated with thyroid dysfunction. Hypothyroidism, both congenital and acquired has been associated with impaired hearing. It has been estimated that a significant hearing loss is found in $25 \%$ of adult hypothyroid patients. ${ }^{[15]}$ The presence of optimal thyroid hormones is required to improve excitability of neuronal pools (generators) in brainstem. It has been shown that thyroid hormone do influence synthesis and release of neurotransmitter and sensitivity of receptors, particularly $\mathrm{H} 1$ and $\mathrm{H} 2$ receptors in the brain. Thus in hypothyroid state, sensory functions might be deranged.The functional integrity of the auditory pathway depends on the intact anatomical pathway, functional relay stations, myelination and thickness of the tract and absence of any compression or pressure from outside. Values of ABR (particularly the absolute and inter-peak latencies) represents the peripheral (from acoustic nerve and pontomedullary portion) and central (pontomesencephalic) conduction time. The abnormal values may indicate that in hypothyroid state there may be some slow conduction at the periphery. ${ }^{[16]}$ It may be caused in part by a general diminution in cerebral activity; a myxoedematous infiltration of the middle ear has also been postulated to explain loss of conduction. ${ }^{[17]}$ These abnormalities in Auditory Brainstem Responses can also be explained by the low body temperature seen in these patients. ${ }^{[18]}$ Hypothyroidism is associated with significant neurocognitive deficits because hypothyroidism prevents the brain from adequately sustaining the energy consuming processes needed for neurotransmission, memory and other higher brain functions. ${ }^{[19]}$ Thus it is indicated that hypothyroidism accounts for delayed neural transmission and increased latencies.

Keeping in mind the prevalence of hypothyroidism and its detrimental effects on the hearing ability of an individual, it is suggested that BAEP testing may also be done as a part of routine screening procedures which are of vital importance in hypothyroid patients.

\section{Conclusion}

The results of our study clearly show that even though a hypothyroid patient might be unaware of hearing deficit early in the course of the disease, changes do begin to appear at various levels in the nervous system. As electrophysiological studies are easy to perform and harmless to the subjects, and they may detect subtle CNS changes at peripheral (auditory nerves) and central level (brainstem) at an early stage of 
hypothyroidism, these electrophysiological studies can be used with fair accuracy and non-invasively, to find out any auditory dysfunction as early as possible in hypothyroid patients.awareness should be created among health professionals involved directly or indirectly in the care of hypothyroid patients and to inform general public about the association of auditory decline with hypothyroidism. Education and treatment strategies for the hypothyroid patients have to be planned accordingly. Special care must be given to the hypothyroid patients before a permanent damage to auditory pathway occurs. In our study we included the subjects with normal hearing without any clinical signs and symptoms of deafness, but affected waves of BAER recordings suggest that the auditory pathway is affected significantly. So close follow up is necessary in hypothyroid patients. Also because of extremely diverse dietary and also help in standardizing the pattern of BAEP abnormalities in hypothyroidism.

\section{Acknowledgement}

The authors are grateful to all the participants, without whose coordination and active participation, this work would not have been fruitful. We are also thankful to the clinical labs, for their help and support.

\section{References}

[1]. Silverthorn, Dee Unglaub. Endocrine control of growth and metabolism. In: Human physiology: an integrated approach. $5^{\text {th }}$ edi. Pearson Education, Inc. 2010; 23:764-68.

[2]. Longo, Fauci, Kasper, Hauser, Jameson, Loscalzo. Disorders of the Thyroid Gland. In: Harrison's principles of Internal Medicine. $18^{\text {th }}$ edi. McGraw-Hill. 2012;341:2911-19.

[3]. Hall J.E. Thyroid Metabolic Hormones. In: Guyton and Hall Textbook of Medical Physiology. 12 ${ }^{\text {th }}$ edi. Elsevier. $2011 ; 76: 917$.

[4]. Melmed S, Polonsky K S, Larsen P R, Kronenberg H. M. Hypothyroidism and Thyroiditis. Williams Textbook of Endocrinology.12 $2^{\text {th }}$ edi. Elsevier. 2011;13:410.

[5]. Ritter FN. The effects of hypothyroidism upon the ear, nose and throat. Laryngoscope. 1967;77:1427-79.

[6]. Oliveira JAA. Fisiologia da Audição - Cócleaativa In: Figueiredo MS. EmissõesOtoacústicas e BERA. São José dos Campos: Pulso Editorial; 2003.p.1-34.

[7]. Di Lorenzo L, Foggia L, Panza N, Calabrese MR, Motta G, Tranchino G, et al. Auditory brainstem response in thyroid diseases before and after therapy. Horm Res. 1995;43:200-5.

[8]. Santos KT, Dias NH, Mazeto GM, Carvalho LR, Lapate RL, Martins RH. Audiologic evaluation in patients with acquired hypothyroidism.Braz J Otorhinolaryngol. 2010;76(4):478-84.

[9]. Lisowska G, Namyslowski G, Morawski K, Strojek K. Early Identification of Hearing Impairment in Patients with Type 1 Diabetes Mellitus.OtolNeurotol 2001;22(3):316-20.

[10]. Chaudhari L, Tandon OP, Vaney N, Agarwal N. Auditory Evoked Responses in Gestational Diabetics. Indian J PhysiolPharmacol 2003;47(1):75-80.

[11]. Gupta R, Aslam M, Hasan SA, Siddiqi SS. Type-2 diabetes mellitus and auditory brainstem responses-a hospital based study. Indian J EndocrinolMetab 2010;14(1):9-11.

[12]. Misra UK and Kalita J. Brainstem auditory evoked potentials. In: Clinical Neurophysiology (2nd edn.). New Delhi: Elsevier India 2006;329-45.

[13]. Biacabe B, Chevallier JM, Avan P, Bonfils P. Functional anatomy of auditory brainstem nuclei : Application to the anatomical basis of brainstem auditory evoked potentials. Auris Nasus Larynx 2001;28:85-94.

[14]. Guideline 9C : Guidelines on short latency auditory evoked potentials. American Clinical Neurophysiological Society, 2008. (Accessed September 1, 2021 at http://www.acns.org/pdfs/Guideline \% 209C1.pdf ).

[15]. Meyerhoff WL. Hypothyroidism and the ear: electrophysiological, morphological, and chemical considerations. Laryngoscope. 1979 Oct;89(10 Pt 2 Suppl 19):1-25.

[16]. Anjana Y, Vaney N, Tandon OP, Madhu SV. Functional status of auditory pathways in hypothyroidism: evoked potential study. Indian J PhysiolPharmacol. 2006 Oct-Dec;50(4):341-9.

[17]. Howarth AE, Llyod HED. Perceptive Deafness in Hypothyroidism.Brit Med Jour 1956; 1: 431-433.

[18]. Thornton AR, Jarvis SJ. Auditory brainstem response findings in hypothyroid and hyperthyroid disease.ClinNeurophysiol. 2008 Apr;119(4):786-90.

[19]. Sharma K, Behera JK, Sood S, Rajput R, Satpal, Praveen P. Study of cognitive functions in newly diagnosed cases of subclinical and clinical hypothyroidism. J Nat SciBiol Med. 2014 Jan;5(1):63-6. 